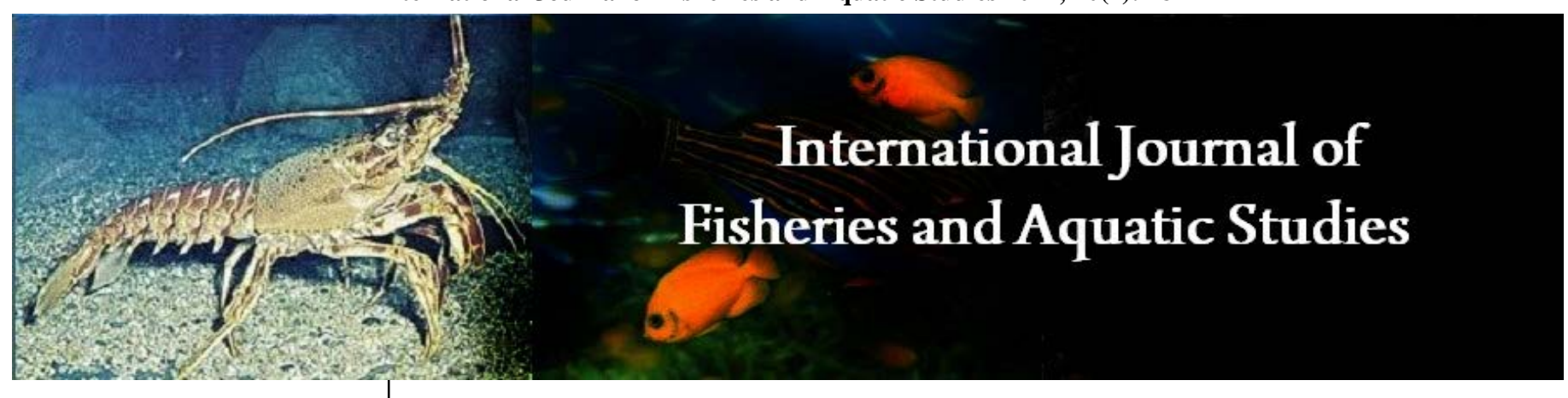

E-ISSN: 2347-5129

P-ISSN: 2394-0506

(ICV-Poland) Impact Value: 5.62

(GIF) Impact Factor: 0.549

IJFAS 2022; 10(1): 18-22

(C) 2022 IJFAS

www.fisheriesjournal.com

Received: 05-11-2021

Accepted: 07-12-2021

Fittrie Meyllianawaty Pratiwy Department of Fisheries, Faculty of Fisheries and Marine Sciences, Universitas Padjadjaran,

Indonesia

Muhamad Dwi Cahya

Graduate Program in Fisheries

Science, Faculty of Fisheries and

Marine Sciences, Universitas

Padjadjaran, Indonesia

Jl. Raya Bandung-Sumedang,

Km. 21 Hegarmanah,

Jatinangor, Sumedang, Jawa

Barat, Indonesia

Yuli Andriani

Department of Fisheries, Faculty of Fisheries and Marine Sciences, Universitas Padjadjaran,

Indonesia
Corresponding Author:

Muhamad Dwi Cahya

Graduate Program in Fisheries

Science, Faculty of Fisheries and

Marine Sciences, Universitas

Padjadjaran.

Jl. Raya Bandung-Sumedang,

Km. 21 Hegarmanah,

Jatinangor, Sumedang, Jawa

Barat, Indonesia

\section{Digitization of aquaculture: A review}

\author{
Fittrie Meyllianawaty Pratiwy, Muhamad Dwi Cahya and Yuli Andriani
}

DOI: https://doi.org/10.22271/fish.2022.v10.i1a.2623

\begin{abstract}
Industrial revolution 4.0 is a transition from manual process to automation processes were based on computer technology capabilities. Technological development towards the use of the Internet of Things (IoT) and Big Data must begin with the digitization process in all sector, including fisheries and aquaculture. Digitization in fisheries has brought many changes to the process of cultivation and catching fish. Time, cost, and labor efficiency are the main advantages of digitizing fisheries. The purpose of this paper is to determine the extent to which the digitization in fisheries, especially aquaculture, the method used in this paper is systematic literature review. The process of digitizing aquaculture can be seen from various aspects, including pre-production aspects (determination of cultivation locations using GIS), production aspects (using automatic feeders and automatic water quality testing tools can improve resource efficiency), and post-production aspects (utilization of digital marketing).
\end{abstract}

Keywords: Automatic feeder, digital marketing, digitization of fisheries, IoT, GIS

\section{Introduction}

The industrial revolution 4.0 was a period where there is an automation process based on the ability of computer technology. Industrial revolution 4.0 has the aim of introducing and creating smart factories whose activities are improved and transformed by technology using CPSs (Cyber-Physical system), IoT (Internet of Things), and big data ${ }^{[1]}$. IoT is a term introduced by Kevin Ashton in 1999 with the basic concept of computing that allows an object (or thing) to hear, see, think and work by utilizing information in making a decision ${ }^{[2]}$. Technological developments towards IoT and big data must begin with the digitization process in all fields, including fisheries.

Digitization in fisheries has brought many changes to the way of cultivation and catching fish. Time, cost, and labor efficiency are the main advantages of digitizing fisheries. Digitization of fisheries had started since the emergence of the industrial revolution 3.0 in 1969 there was a transition from manual to automatic production processes by utilizing electronic tools and information technology ${ }^{[1]}$, the application of GPS (Global Positioning System) or the remote sensing system as a satellite-based navigation system used on fishing vessels ${ }^{[3]}$. The development of science and technology has made the world borderless, exchange of information and even data between countries has become more accessible in a concise time. Digitization in fisheries aims to prevent IUU fishing, managing of fishing areas, optimize land conditions, mapping of aquaculture area, and even make labor efficient.

As a maritime country with abundant fishery resources, Indonesia must to take advantage of digitization and even participate in technology development, especially in fisheries that aims to maximize the potential of existing resources. In addition, it is also necessary to have a record of the digitization of fisheries in Indonesia to becomes an illustration of the use of technology, especially in aquaculture. The utilization of technology to determine the location of cultivation by application GIS ${ }^{[4]}$ is an effort to increase efficiency, reduce environmental impacts and plan sustainable cultivation activities. After the cultivation location is determined, the application of technology is continued in the cultivation process such as the use of automatic feeders ${ }^{[5,6]}$, and automatic monitoring water systems ${ }^{[7]}$ to increase production, increase the feeding conversion ratio and provide real-time water quality data. This paper aims to know and provide information about the description of digitization and the use of IoT in fisheries, especially aquaculture. 


\section{Method}

The method used in writing this literature review is a systematic and explicit method to analyze, identify and synthesize the data that has been collected in accordance with the topic of writing ${ }^{[8]}$. The data was carried out in OctoberDecember 2021. The data type is secondary data obtained based on previous research and writings. The secondary data can be sourced from reputable national and international journals and other supporting books. Data search is done by utilizing databases from websites such as Google Scholar, Google Books, ScienceDirect, and Elsevier.

Search literature using keywords that are following the topic of writing, including the Internet of Things (IoT), Fisheries, Aquaculture, Digitization, Big Data, Industrial Revolution, Automatic Feeder, Feed, Online Marketing, Marketplace and Geographic Information Systems. Inclusion and exclusion criteria used data sources consist of (table 1):

Table 1: Inclusion and Exclusion Criteria

\begin{tabular}{|c|c|c|}
\hline Criteria & Inclusion & Exclusion \\
\hline General Topics & Studied that provide IoT, big data, technology, and digitization in \\
aquaculture & $\begin{array}{c}\text { Studied that out of technological support in } \\
\text { aquaculture }\end{array}$ \\
\hline Study Design & All types of studies & - \\
\hline $\begin{array}{c}\text { Publication } \\
\text { Years }\end{array}$ & Journals and books with publications after 1993 & Journals and books before 1993 \\
\hline Language & Indonesian and English & Outside Indonesian and English \\
\hline Publication type & Articles published in national and international journals & Articles published but no available source \\
\hline
\end{tabular}

The articles from search strategies were filtered with inclusion and exclusion criteria, there were 32 articles according to the topic of writing, and then there were two articles that were not published in national or international journals. Based on the inclusion and exclusion criteria, the final selection are 30 articles can be used in this paper.

\section{Results and Discussion}

\subsection{Definition of Digitization in Fisheries Sector}

The development of science in communication and technology affected to fishery activities. Trendov ${ }^{[9]}$ state that digitization is a solution created by the industrial revolution 4.0, this is because the fisheries sector is part of agri food which must ensure the creation of food security to meet the needs of 9.6 billion people in 2050. Multiple forms of digitization in fisheries sector, must be used to access the latest information, know market developments, calculate input and output, and increase production to make fisheries activities more efficient, both in terms of economy, labor, and time.

The Internet of Things (IoT) is a concept that allows various objects to communicate with each other, exchange information, and even make joint decisions by utilizing information technology and computational processes ${ }^{[2]}$. The term IoT has been known since 1999 and was presented by Kevin Ashton, the founder of the MIT Auto-ID Center. There were three categories regarding the definition of IoT, namely the interaction via the internet between people to people, people to machines, and machine to machine. The purpose of IoT is to allow an object to be connected anytime and anywhere, with anything and anyone who uses various networks to make human activities easier ${ }^{[10]}$.

De Mauro [11] was stated that the notion of big data is a collection of information that has the character of a high volume, velocity and variety of data that requires technology and specific analytical methods to transform it into something more valuable. The digitization process started with a massive transformation from analog signals to digital signals in the early 1990s. Analog signals that have been transformed into digital format, will be structured into a data set structure. Currently, big data technology has developed very rapidly, this development was triggered by three main factors consisting of a) the rapid development of data storage capabilities, b) the rapid development of data processing engine capabilities and c) the abundance of data availability
[12]. The utilization of the internet of things and big data has been widely carried out in various sectors, one of which is aquaculture.

\subsection{Utilization of Digitalization in Aquaculture Sector Aquaculture}

\subsubsection{Determination of Locations with GIS}

As previously explained, fishery digitization is an effort to increase productivity and streamline existing resources. Remote sensing is used to find potential locations for fishing and can also be applied to determine the suitability of aquaculture locations. Determination of location aims to increase the efficiency of time and existing resources. Maeden \& Aguilar-Manjarrez ${ }^{[13]}$ stated that the development and exploration of GIS systems experienced a huge increase in the early 1995s, because geospatial investigation was increasingly crowded, and used in various fields of study. Furthermore, the use of GIS for fisheries is an attempt to increase the success of fishery activities and some of the data needed to determine the success of production include economic aspects, social aspects, physical or biological aspects and sustainability aspects ${ }^{[13]}$.

The use of GIS has been widely carried out in various fields of study because GIS can analyze, organize, and display a wide variety of spatial data ${ }^{[14]}$. The selection of aquaculture location needs to be based on physical, chemical, and biological qualities that will obtain sustainable aquaculture. The data of environmental quality and land suitability will be presented in a thematic map to make it easier to read and understand the results of data interpretation ${ }^{[15]}$. The advantage of using GIS in determining the location of aquaculture is that it obtains more comprehensive and detailed data so that it helps in planning aquaculture activities, resource management, and land used.

Determination of the location is crucial in aquaculture because the ideal area will increase the efficiency of cultivation activities and reduce environmental impacts due to cultivation activities ${ }^{[4,16]}$. The application of GIS combined with multi-criteria decision making methods (MCDM) would result in the optimum location for aquaculture activities, because the combination of GIS and MCDM will produce more data to improve quality of final decisions [17]. Digitization in the pre-cultivation phase will obtain more mature, comprehensive, and long-term planning of aquaculture activities. 


\subsubsection{Utilization of Automatic Feeder Technology}

Sandra [18] and Andriani [19] stated that in aquaculture activities, feed is the most important thing that determines the success of aquaculture activities because the availability of feed spend $60-70 \%$ of production costs. Based on these several things, the provision of feed to aquaculture commodities must be carried out as efficiently as possible, both in terms of quantity, quality, and the method of appropriation of feed. Technological advances made modernization and more efficient fish farming activities by presenting automatic feeders. An automatic feeder is a tool to provide fish feed automatically which can be controlled based on time ${ }^{[20]}$, water temperature ${ }^{[21]}$, telephone calls ${ }^{[22]}$, feeding behavior ${ }^{[23]}$, self-feeding ${ }^{[24,6]}$, acoustic feedback ${ }^{[5,25]}$ and mobile robotics ${ }^{[26]}$

Karunia \& Marinasari ${ }^{[27]}$ stated that an automatic feeder could suppress externalities from cultivation activities is to providing measurable feed using an automatic feeder. Rahayani \& Gunawan ${ }^{[20]}$ designed an automatic feeder device using a microcontroller to throw feed and regulated based on the schedule was set before automatic feeder has applied. The microcontroller can also notify farmers when the feed storage container has run out. Another study uses water temperature to control automatic feeders [21]. The automatic feeder developed because the growth rate and fish appetite can be affected by the state of the water temperature. An automatic feeder controlled by water temperature can regulate the time and amount of feed given to cultivated commodities with the results of the analysis carried out by the microcontroller. Suratno ${ }^{[22]}$ designed an automatic feeder controlled by phone. The phone assembled in an automatic feeder would turn on when there was an incoming call, which would then provide an electric voltage to drive the dynamo, and feed automatically may fall into the cultivation tank.

Zhou ${ }^{[23]}$ utilize a camera used as machine vision to determine the feeding activity of cultivated species. The images obtained through the camera will be processed and analyzed by the microcontroller to extract behavioral indicators, if the fish in the tank swim around and no reaction to the feed, the microcontroller sends an instruction to stop the feeding machine. The result shows that the use of automatic feeders programmed based on the fish behavior can reduce feed residues so that the impact on water quality is more maintained and make feeding more efficient. Noble [24] designed an automatic feeder controlled by fish or named by self-feeder. Self-feeder was using a switch with orange bead, a diameter of $5 \mathrm{~mm}$, and placed in the middle of the culture container. When the fish pulls the bead, it will activate the SS-5GL sensor to rotate the feed storage container by $90^{\circ}$ so that the feed will go down to the culture container. Pratiwy ${ }^{[6]}$ conducted a study by comparing the growth quality of fish using a self-feeder indoors and outdoors. The results found that the application of a self-feeder is an effective method for use in tilapia farming with the requirement that the water temperature must be warm enough $\left(24-26^{\circ} \mathrm{C}\right)$ to maintain the physiological condition of tilapia.

In contrast to Zhou, research conducted by Napaumpaiporn [5] and Ullman ${ }^{[25]}$ used a hydrophone to regulate the feeding carried out by the automatic feeder. The automatic feeder is designed to use a sound detection device in the water (hydrophone) to determine the level of feed consumption by aquaculture commodities by utilizing the sound produced when fish or shrimp are eating ${ }^{[5]}$. However, the automatic feeder is only used from 07.00 to 19.00 because the hydrophone cannot detect sound when the aerator is turned on [25]. Both studies state that the use of automatic feeders using acoustic feedback has a significant growth rate and effectiveness feeding compared to feeding using an automatic feeder regulated by schedule.

Various kinds of innovations in feed technology have been developed to increase production of aquaculture commodities and reduce the negative impact of inedible feed waste. In most of today's commercial fish farming, feeding technologies such as automatic feeders have been widely used. Using an automatic feeder, errors in how to feed manually that are stocked can be avoided. In other words, this tool is very effective in improving feed management. Selffeeding or demand feeder is modified from the automatic feeder. This feeding method utilizes the fish's appetite based on the fish's diet. The automatic feeder aims to decrease feed conversion, better growth rate, and reduce uneaten feed. Several studies have been conducted to support this claim, such as the European Seabass (Dicentrarchus labrax) ${ }^{[28]}$, Yellowtail (Seriola quinqueradiata) [29], and Tilapia (Oreochromis niloticus) ${ }^{[30]}$.

Using robots to make human activities easier is the goal of the 3.0 industrial revolution. Utilizing technological developments, Von Borstel ${ }^{[26]}$ designed a robot that functions to replace human tasks in feeding in aquaculture activities. The mobile robot (MR) is a device that moves on a rail (monorail) with four wheels, providing in the form of quantity, location of ponds or tank, and feeding time is programmed into the MR before applied. Furthermore, MR can perform its duties in automatic mode (using an embedded program) or supervised mode (by utilizing the internet connection to the computer). The use of this feeding robot is an effort made to facilitate fish farming or research activities, minimize errors, especially in research activities and increase the efficiency of aquaculture activities.

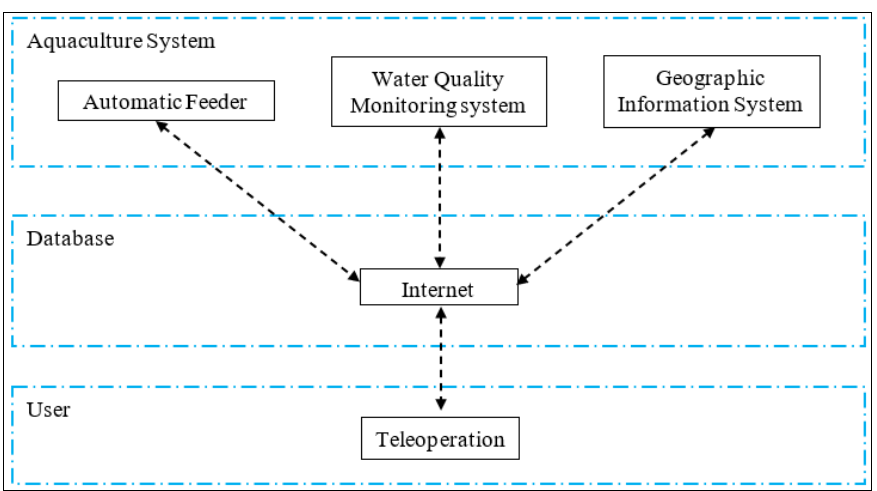

Source: Von Borstel ${ }^{[26]}$ (Modified)

Fig 1: Utilization of IoT in Aquaculture

\subsubsection{Automatic Water Quality Testing}

In addition to the availability and good quality of feed, the success of aquaculture activities is also largely determined by water quality. $\mathrm{Hu}$ [31] explained that protecting the environment and ecological aspects by maintaining water quality is crucial to ensure that aquaculture activities are more efficient. Good water quality in aquaculture activities will support fish growth and reduce the likelihood of fish getting the disease ${ }^{[32]}$. Several parameters that must be known to ensure the success of aquaculture activities include dissolved oxygen (DO), $\mathrm{pH}$, temperature, ammonia, nitrate, and salinity (for aquaculture activities in brackish-sea waters) [33]. Furthermore, Simbeye \& Yang [33] explained that these 
parameters need to be known because they have a significan influence on the success of aquaculture, such as temperature affects fish growth and appetite, DO affects growth, stress levels, activity, and mortality of fish. $\mathrm{pH}$ affects the toxicity of ammonia because high $\mathrm{pH}$ (alkaline conditions) will increase the toxicity of anionic ammonia.

Real-time data is an essential tool that must be had in intensive aquaculture systems because a slight water change will affect fish physiology [31]. An automatic water quality monitoring system with real-time conditions is necessary to support aquaculture success. Various studies were conducted to improve the ability to monitor water quality. Zhu ${ }^{[7]}$, Simbeye \& Yang ${ }^{[33]}$, and Hongpin ${ }^{[34]}$ built technology to control water quality using network wireless. López [35] designed a monitoring tool by utilizing open-source hardware at a low price. Tolentino ${ }^{[32]}$ built the water quality monitoring system with IoT.

These studies give the same results. The application of an automatic water quality monitoring system makes aquaculture activities easier because water quality data will be reported continuously that be required to make a decision. These data are provided to decide stage to do, add or reduce feeding, increase or decrease fish density and make water change or not. Thus, fish farming activities will be more efficient and effective with the digitization of water quality control.

\subsubsection{Selling Aquaculture Products in Online Market}

Transformation is not only in pre-and cultivation activities as determining aquaculture locations using GIS, smart aquaculture, automatic feeders, and automatic water quality monitoring system but also post-cultivation activities specifically in the marketing of aquaculture products. The development of information and technology makes the market move to the online market or named e-commerce. The online market can reduce prices in the supply chain, increase profits for fish farmers and expand the market share of aquaculture products ${ }^{[36]}$. Online marketing is a perfect solution for disseminating aquaculture products because Indonesia had more than 100 million social media users ${ }^{[37]}$ so this will be a big opportunity in product marketing.

Digital product marketing is a solution to the problem of marketing agricultural products in Indonesia, which is known for its long supply chain and affects the selling price of these products. However, in addition to influencing the supply chain of a product, it turns out that online marketing activities also affect consumer behavior, this is explained by Muninggar \& Aulia [38] in their research which states that $60 \%$ of respondents choose to shop for aquaculture products through online marketing because it is more practical, $67 \%$ satisfied with the price range and quality of products offered through online marketing and $89 \%$ of respondents made product purchases again. This shows that online marketing can become a marketing channel that has the potential to continue to be developed by increasing practicality and competitive prices and product quality.

\section{Conclusion}

Advances in science, technology, and information make human activities easier, including in the aquaculture sector. Digitization in aquaculture leads to an efficiency of time, resources, and cost of productions, minimizes the externalities of aquaculture activities, and increases aquaculture production. The process of digitizing aquaculture can be seen from various aspects, including the pre-production aspect, where the activity of determining the location of aquaculture using GIS can provide more comprehensive results, more mature planning and can be applied in the long term, based on the production aspect, where aquaculture activities by utilizing the automatic feeder and automatic water quality testing tools can increase resource more efficient, reduce the amount of uneaten feed, maintain water quality and increase aquaculture production, while the post-production aspect of using digitization in marketing provides added value to sales including more practicality, cheaper prices and guarantee product quality.

\section{References}

1. Dobrzański LA, Dobrzańska-Danikiewicz AD. Why are Carbon-Based Materials Important in Civilization Progress and Especially in the Industry 4.0 Stage of the Industrial Revolution. Materials Performance and Characterization. 2019;8(3):337-370.

2. Jamaludin RA, Purba F, Effendy, Muttaqin MY, Raynonto D, Chamidah MA, et al. Future Technology Trend. Medan. Yayasan Kita Menulis. 2020, 213.

3. Suhelmi IR, Yulius D, Purbani. The Management of Fisheries Resource Based on Fisheries Management Zone (FMZ) using WebGIS Technology. Depik. 2013;2(2):7075.

4. Nayak AK, Pant D, Kumar P, Mahanta PC, Pandey NN. GIS-based Aquaculture Site Suitability Study Using Multi-criteria Evaluation Approach. Indian Journal Fisheries. 2014;61(1):108-112.

5. Napaumpaiporn T, Chuchird N, Taparhudee W. Study on the Efficiency of Three Different Feeding Techniques in the Culture of Pacific White Shrimp (Litopenaeus vannamei). Kasetsart University Fisheries Research Bulletin. 2013;37(2):8-16.

6. Pratiwy FM, Kohbara J, Dhahiyat Y, Sunardi. Effectiveness of the Self-feeding Method on Growth Performance of Nile Tilapia, Oreochromis niloticus. Aquaculture Science. 2017;65(4):367-375.

7. Zhu X, Li D, He D, Wang J, Ma D, Li F. A Remote Wireless System for Water Quality Online Monitoring in Intensive Fish Culture. Computers and Electronics in Agriculture. 2010;71:3-9.

8. Triandini E, Jayanatha S, Indrawan A, Putra GW, Iswara B. Systematic Literature Review Method for Platform Identification and Development of Information System in Indonesia. Indonesia Journal of Information System. 2019;1(2):63-77.

9. Trendov NM, Varas S, Zeng M. Digital Technologies in Agriculture and Rural Areas: Briefing Paper. Rome. FAO. 2019, 26 hlm. https://www.fao.org/3/ca4887en/ca4887en.pdf.

10. Patel KK, Patel SM. Internet of Things-IOT: Definition, Characteristic, Architecture, Enabling Technologies, Application \& Future Challenge. International Journal of Engineering Science and Computing. 2016;6(5):61226131.

11. De Mauro A, Greco M, Grimaldi M. A Formal Definition of Big Data Based on its Essential Features. Library Review. 2016;65(3):122-135.

12. Maryanto B. Big Data and Utilizing in many Sectors. Media Informatika 2017;16(2):14-19.

13. Maeden GJ, Aguilar-Manjarrez J. Advances in Geographic Information System Systems and Remote Sensing for Fisheries and Aquaculture. Rome. 2013, 111 
hlm. https://www.fao.org/3/i3102e/i3102e.pdf.

14. Gusmawati NF, Andayani A, Mu'awanah U. Utilization of Very High Remote Sensing Imagery for Aquaculture Ponds Mapping in Ujung Pangkah District, Gresik. Jurnal Kelautan Nasional, 2017;11(1):35-51.

15. Utojoh A, Mustafa, Rachmansyah, Hasnawi. Site Selection for Sustainable Brackishwater Ponds Culture Development using Geographic Information System in South Lampung Regency. Journal Riset Akuakultur, 2009;4(3):407-423.

16. Gál D, Pekár F, Kerepeczki É. A Survey on the Environmental Impact of Pond Aquaculture in Hungary. Aquaculture International. 2016;24:1543-1554.

17. Ghobadi M, Nasri M, Ahmadipari M. Land Suitability Assessment (LSA) for Aquaculture Site Selection via in Integrated GIS-DANP Multi-criteria Method; a Case Study of Lorestan Province, Iran. Aquaculture, 2020;530:735-776.

18. Sandra MA, Andriani Y, Haetami K, Lili W, Wiyatna MF. Effect of Adding Fermented Restaurant Waste Meal with Different Concentration to Physical Quality of Fish Pellet. Asian Journal of Fisheries and Aquatic Research, 2020;5(3):1-7.

19. Andriani Y, Nurhayati A, Zidni I, Cahya MD. Financial Analysis of Costs of Fish Feed Production with Restaurant Waste as Basic Ingredients (Case Study in Jatinangor District, Sumedang Regency, West Java). Asian Journal of Fisheries and Aquatic Research. 2021;14(5):55-60.

20. Rahayani RD, Gunawan A. Proposed Design of an Automatic Feeder and Aerator Systems for Shrimps Farming. International Journal of Materials, Mechanics and Manufacturing. 2018;6(4):277-280.

21. Pratisca S, Sari J. Automatic Feeder based on Water Temperature in Fish Pond. Journal Teknik Elektro Indonesia. 2020;1(2):193-200.

22. Suratno S, Kurniawan F, Muharis. Automatic Feeder for Fish Feed Controlled by Hand phone (Teleautofeeder). Prosiding Forum Inovasi Teknologi Akuakultur. 2013, 729-732.

23. Zhou C, Lin K, Xu D, Sun C, Chen L, Zhang S, Guo Q. Computer Vision and Feeding Behavior Based Intelligent Feeding Controller for Fish in Aquaculture. International Federation for Information Processing. 2019, 98-107.

24. Noble C, Mizusawa K, Suzuki K, Tabata M. The Effect of Different Self-feeding Regimes on the Growth, Behaviour and Fin Damage of Rainbow Trout Held in Groups. Aquaculture. 2007;264:214-222

25. Ullman C, Rhodes MA, Davis DA. Feed Management and the Use of Automatic Feeders in the Pond Production of Pacific White Shrimp Litopenaeus vannamei. Aquaculture. 2018;498:44-49.

26. Von Borstel FD, Suárez J, de la Rosa E, Gutiérrez J. Feeding and Water Monitoring Robot in Aquaculture Greenhouse. Industrial Robot: an International Journal. 2013;40(1):10-19.

27. Karunia S, Marinasari R. Externality Cost Analysis of Floating Cage Business Waste Feed in the Jatiluhur Reservoir, Purwakarta Regency. Buletin Ilmiah Marina Sosial Ekonomi Kelautan dan Perikanan. 2015;1(2):7788.

28. Sánchez-Vázquez FJ, Martínez M, Zamora S, Madrid JA. Design and performance of an accurate demand feeder for the study of feeding behaviour in sea bass,
Dicentrarchus labrax L. Physiology \& behavior. 1994;56(4):789-794.

29. Kohbara J, Hidaka I, Kuriyama I, Yamashita M, Ichikawa M, Furukawa $\mathrm{K}$ et al. Nocturnal/Diurnal Demand-feeding Pattern of Yellowtail Seriola quinqueradiata under Different Keeping Conditions. Fisheries Science. 1994;66(2000):955-962.

30. Pratiwy FM, Kohbara J. Dualistic Feeding Pattern of Nile Tilapia (Oreochromis niloticus, L.) Reared under Different Self-Feeding System Conditions. Aquaculture Research. 2018;49(2):969-976.

31. Hu Z, Li R, Xia X, Yu C, Fan X, Zhao Y. A Method Overview in Smart Aquaculture. Environmental Monitoring Assessment. 2020;192(8):1-25.

32. Tolentino LKS, De Pedro CP, Icamina JD, Navarro JBE, Salvacion LJD, Sobrevilla GCD et al. Dovelopment of an IoT-based Intensive Aquaculture Monitoring System with Automatic Water Correction. International Journal of Computing and Digital Systems. 2020;9:1-11.

33. Simbeye DS, Yang SF. Water Quality Monitoring and Control for Aquaculture Based on Wireless Sensor Networks. Journal of Networks. 2014;9(4):840-849.

34. Hongpin L, Guanglin L, Weifeng P, Jie S, Qiuwei B. Real-time Remote Monitoring System for Aquaculture Water Quality. International Journal of Agricultural and Biological Engineering. 2015;8(6):136-143.

35. López RAB, Cordova LRM, Nuñez JCG, Galaviz JRG, Gamez JCI, Hernandez RC. Implementation and Evaluation of Open-Source to Monitor Quality in Precision Aquaculture. Sensors. 2020;20:3-15.

36. Heriawan F, Susanto AB, Haryanti D. Information Technology based Marketing, Sales and Production Strategy of Processed Seaweed during the Covid-19 Pandemic in Padepokan Suket Segoro Semarang. Journal of Marine Research. 2021;10(1):138-146.

37. Rewah JM. The Influence of Information Technologybased Promotion on Young Entrepreneur of Klabat University. Cogito Smart Journal. 2018;4(1):24-36.

38. Muninggar R, Aulia H. Costumer Perception on Digital Marketing of Fishery Products in Jakarta. Albacore 2020;4(3):257-269. 